\title{
Short Circuit and \\ Contingency Analysis Implementation for IEEE-14 Bus System using Mi Power Software
}

\author{
Mr.A.Prabhu' ${ }^{1}$, Mr.A.Subramaniya Siva ${ }^{2}$ \\ Assistant Professor, Department of EEE, K.Ramakrishnan College of Engineering, Tamilnadu, India ${ }^{1,2}$
}

\begin{abstract}
In this paper we have explained about the performance of IEEE-14 bus system by using Mi power technology. In the previous project the load flow analysis and stability analysis was found by using Mi power software. This project shows the short circuit and contingency analysis by using MI power technology. The maximum \& minimum real and reactive power limit have been set $\&$ the results are obtained. The output result was found more efficient compared to the previous model. All the power system equipments were designed to withstand high efficiency and to withstand worst case condition. The MI power software is the advanced technology in order to improve the load flow analysis, stability analysis, short circuit and contingency analysis. This project explains about the MI power software to which it raises the efficiencies for the calculation of short circuit and contingency analysis. This project explains about the different fault conditions such as symmetrical and unsymmetrical fault analysis in which we are considering about the short circuit analysis. The transient and sub transient components are to be found and the system leads to the stable condition.
\end{abstract}

Keywords: IEEE 14 bus, Contingency Analysis, Mi Power Software 9.1

\section{INTRODUCTION}

The power was generated at the generating stations \& it was feed into the transmission line via step up transformer. The electrical energy was travelled from generation station to the distribution station via the transmission lines. In between the generating station \& distribution various voltage levels was used. High voltage was needed in the generating station \& low voltage is used in the distribution side. The voltage in the distribution side was stepped down using transformer $\&$ it was utilized by the consumers. The electrical power was generated by generators in various forms like Coal, Nuclear, Wind etc., Generally voltage level is usually $11 \mathrm{Kv}, 16.5 \mathrm{KV}, 33 \mathrm{KV}$,. Over long distances more losses may be there so it may be step up to $132 \mathrm{KV}, 220 \mathrm{KV}, 400 \mathrm{KV}$ etc., \& fed in to the sub transmission network \& to the distribution substations. All the substations are situated at the load centers. Mostly the transformers in the commercial $\&$ residential area are step up transformer whereas in the load side we will have step down transformer. Causes of Power System Faults The causes of faults are numerous, e.g. Lightning

- Heavy winds

- Transmission lines faults due to trees

- Vehicles collide with tower

- Short circuit due to birds

- Aircraft collide with the line

- Small organisms entering into switchgear

- Line gets breakdown due to high load

\section{COMMON POWER SYSTEM FAULTS}

Power system faults may be classified as two types; in the order of frequency of occurrence, they are: Un Symmetrical Fault \& Symmetrical Fault The first fault constitutes rigorous unbalanced operating conditions which involves only one or two phases hence referred to as unsymmetrical faults. In the fourth type, a fault involving all the three phases occurs therefore referred to as symmetrical (balanced) fault.

\section{EFFECTS OF POWER SYSTEM FAULTS}

Faults may lead to fire breakout that consequently results into loss of property, loss of life and destruction of a power system network. Faults also leads to cut of supply in areas beyond the fault point in a transmission and distribution network leading to power blackouts; this interferes with industrial and commercial activities that supports economic 
Vol. 8, Issue 5, May 2019

growth, stalls learning activities in institutions, work in offices, domestic applications and creates insecurity at night.

\section{THREE-SEQUENCE IMPEDANCES AND SEQUENCE NETWORKS}

Positive sequence currents give rise to positive sequence voltage, $\&$ the negative sequence current give rise to negative sequence voltages and zero sequence current give rise to zero sequence voltages, hence each network can be regarded as flowing within in its own network through impedances of its own sequence only.

\section{SEQUENCE NETWORK OF SYNCHRONOUS ALTERNATORS}

An unloaded synchronous machine having its neutral earthed through impedance, zn, is shown in fig. 2(a) below. A fault at its terminal causes currents Ia, Ib and Ic to flow in lines. If fault involves earth, a current In flows into the neutral from the earth. This current flows through the neutral impedance $\mathrm{Zn}$.. Thus depending on the type of fault, one or more of the line currents may be zero.

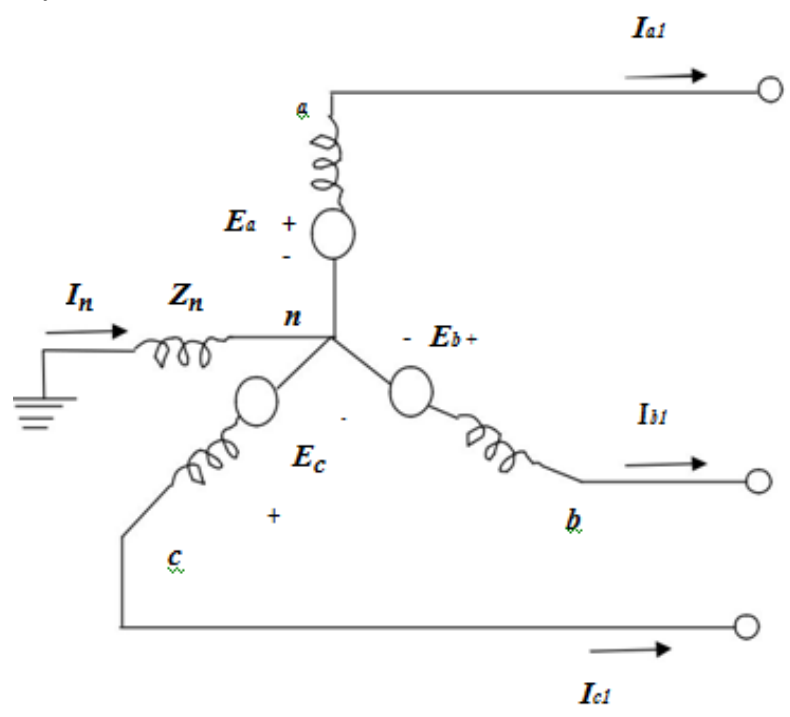

Fig:1 Sequence Network

\section{POSITIVE SEQUENCE NETWORK}

The generated voltages of a synchronous machine are of positive sequence only since the windings of a synchronous machine are symmetrical. Positive sequence network consist of an emf equal to no load terminal voltages and is in series with the positive impedance $\mathrm{Z} 1$ of the machine. Fig shows the paths for positive sequence currents and positive sequence network respectively on a single phase basis in the synchronous machine. The neutral impedance $\mathrm{Zn}$ will disappear in circuit because the phasor sum of Ia1, Ib1 and Ic1 are zero \& no positive sequence current can flow through $\mathrm{Zn}$

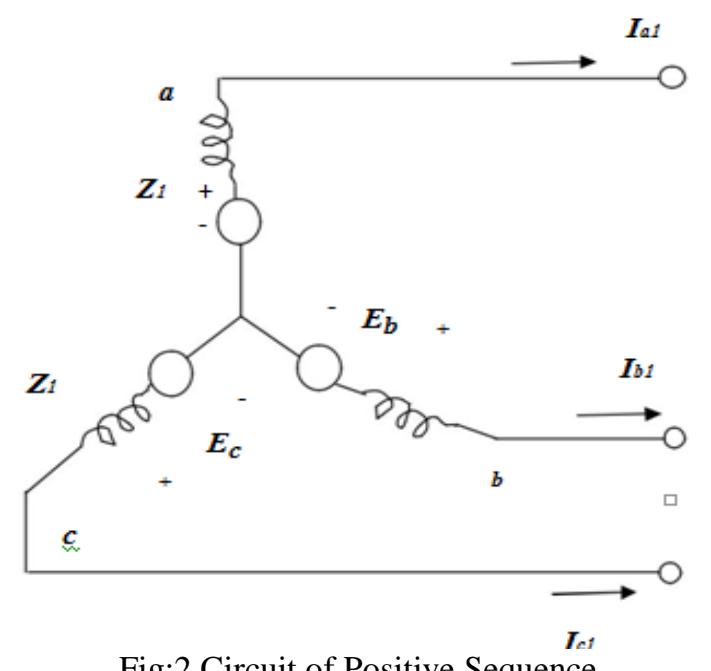

Fig:2 Circuit of Positive Sequence 
Vol. 8, Issue 5, May 2019

\section{NEGATIVE SEQUENCE NETWORK}

A synchronous machine won't generate any negative sequence voltage. Flow of negative sequence currents in the stator winding creates an mmf which rotate at synchronous speed in the direction opposite to direction of rotor, i.e., at double the synchronous speed with respect to rotor.

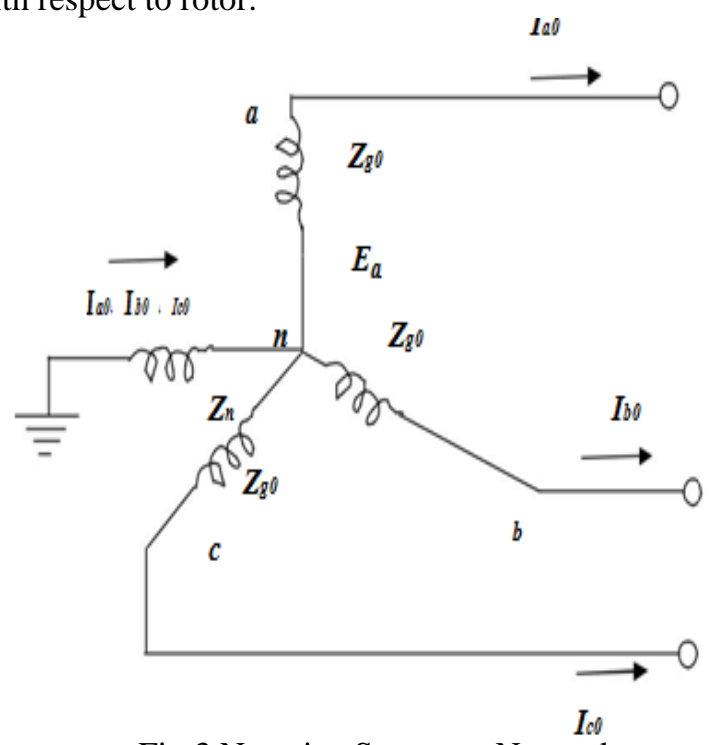

Fig:3 Negative Sequence Network

\section{ZERO SEQUENCE NETWORK}

Zero sequence voltage is not induce in a synchronous machine. The run of zero sequence current in the stator winding produces three mmf which are in the time phase. If each phase winding produced a sinusoidal space mmf, then with the rotor removed, the flux at a point lying on the axis of the stator due to zero sequence current would be zero at every instant. When the flux in the air gap or the leakage flux around slots or end connections is considered, no point in these regions is equidistant from all the three -phase windings of the stator. The mmf produced by a phase winding departs from a sine wave, by amounts which depend upon the arrangement of the winding.

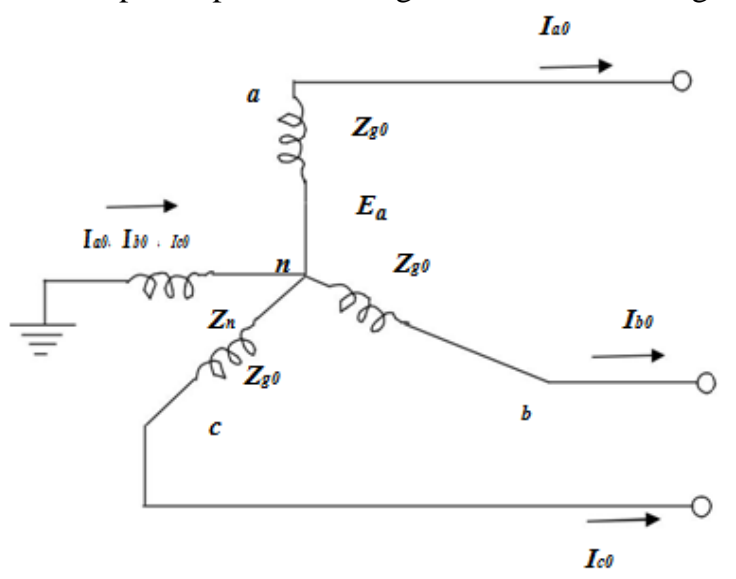

Fig:4 Zero Sequence Network

IX. MI POWER SOFTWARE VERSION 9.1

Mi Power 9.1 is extremely user-friendly windows based software on Power System Analysis. It has set of module for designing the whole power system by simulation diagram. It has a capability to do Load flow analysis, Short circuit analysis, Transient stability, Relay coordination, Line \& cable parameter calculation, Network reduction. Analysis of harmonics \& Dynamic stability can also be analyzed by this software. In this paper we have fin out the contingency \& short circuit analysis of a IEEE 14 bus system. By using this software we can analyze the Planning of power system well before the installation happen 
Vol. 8, Issue 5, May 2019

\section{OUTPUT RESULTS}

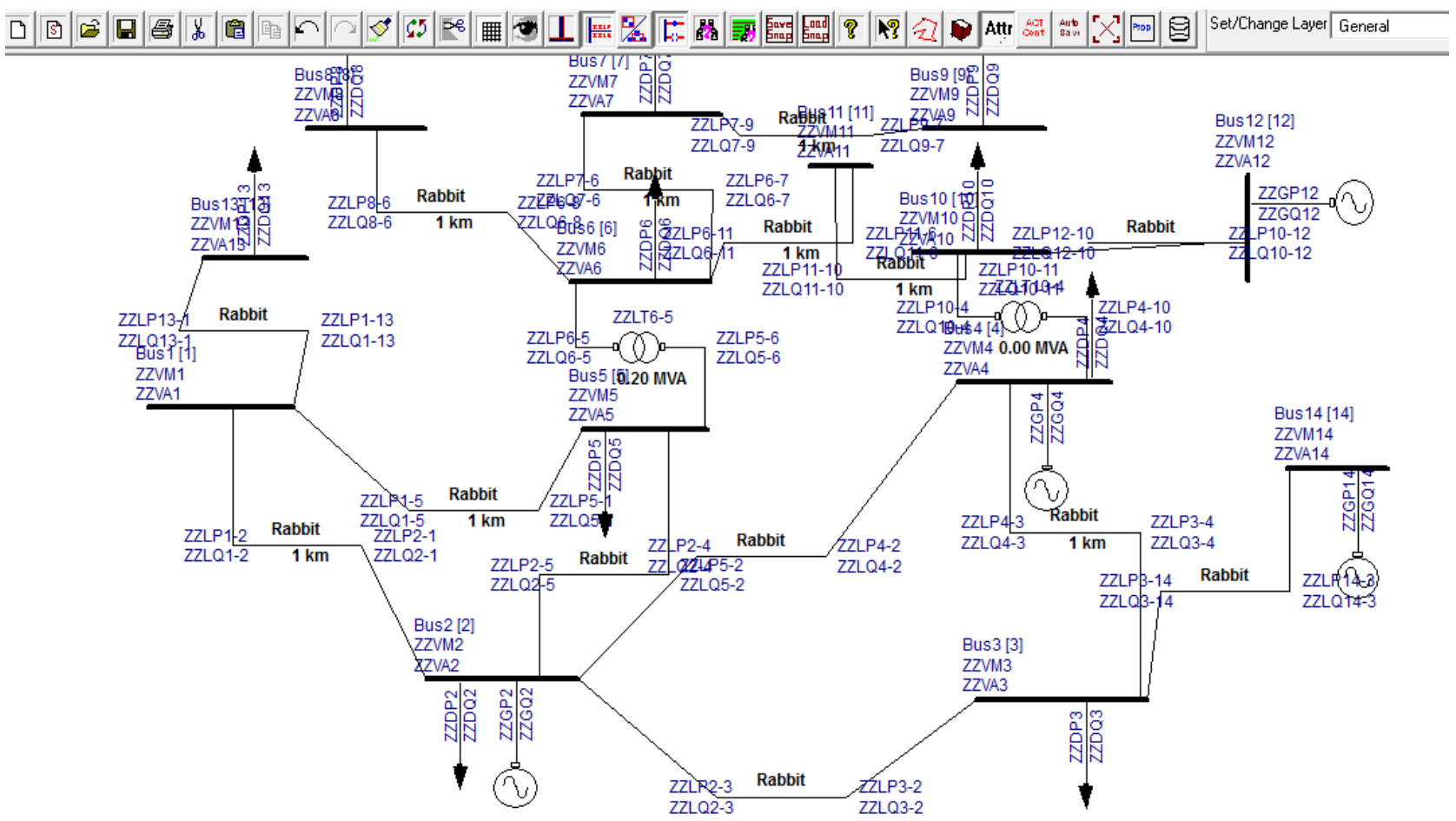

| INPUT DATA |

|***** SYSTEM SPECIFICATION *****|

Largest Bus Number Used $\quad: 14$

Actual Number of Buses $: 14$

Number of Two winding Transformers : 1 Number of Three Winding Transformers : 0

Number of Transmission Lines $\quad: 14$ Number of Series Reactors $\quad: 0$

Number of Series Capacitors $\quad: 00$ Number of circuit Breakers $\quad: 0$

Number of shunt Reactors $\quad: 00$ Number of shunt Capacitors

Number of Shunt Impedances : 0 Number of Generators

Number of Loads : 10

Number of Frequency Relays : : 0

Number of Filters : 0

Number of Convertors

Number of shunt Connected FACTS : $\quad 0$

Number of TCSC Connected $: 0$

Number of UPFC Connected : $\quad 0$

Number of wtg Curves $\vdots 0$

Number of solar plants

Number of Load Characteristics

Number of Gen. Capability Curves

Number of Tie Line Schedules $\quad \vdots 0$

Number of $D C$ Links

Number of Power Injections

Number of SPS Connected

Number of wind Generators

Number of wtg Detailed Curves

contingency Analysis - option

Number of Zones

print option

Plot option

No Frequency Dependent Load Flow, Control option:

Base MVA

Nominal system Frequency $(\mathrm{Hz})$

Frequency Deviation ( $\mathrm{Hz})$

Flows in MW and MVAr, option

slack Bus

Transformer Tap control option

$Q$ checking Limit (Enabled)

Real Power Tolerance (p.u.)

Reactive Power Tolerance (p.u.)

Maximum Number of Iterations

Bus voltage below which Load Model is changed

Circuit Breaker Resistance (p.u.)

circuit Breaker Reactance (p.u.)

Transformer R/X Ratio

4

1

3 - Both Data and Results print

1 - Plotting with p.u. Voltage

0

100.0

50.0

0.0

0

0 (Max. Generation Bus)

0

0.00100

0.00100

15

0.75000

0.00000

0.00010

0.05000 


\% $400.00000 \quad 2.50000 \quad 2.50000 \quad 0.80000$

GENERATOR MULTIPLICATION FACTORS

Negative sequence Resistance

$: 0.17500$

Negative sequence Reactance

$: 0.17500$

zero sequence Resistance

$: 0.03750$

zero sequence Reactance

$: 0.03750$

LOAD MULTIPLICATION FACTORS

Negative Sequence Impedance $: 0.81000$

zero Sequence Impedance $\quad: 1.60000$

$\%$ First Power system Network

\footnotetext{
|

|***** SYSTEM SPECIFICATION $* * * * * \mid$
}

Largest Bus Number used

Actual Number of Buses

Number of Transmission Lines

Number of series Capacitors

Number of shunt Reactors

Number of shunt Impedances

Number of Loads

Number of Frequency Relays

Number of Filters

Number of convertors

Number of shunt connected FACTS

Number of TCSC Connected

Number of UPFC Connected

Number of wtg curves

Number of solar plants

Number of Three winding Transformers

Number of series Reactors

Number of circuit Breakers

Number of shunt capacitors

Number of Generators

Number of Load Characteristics

Number of Gen. Capability Curves

Number of Tie Line schedules

Number of DC Links

Number of Power Injections

Number of SPS Connected

Number of wind Generators

Number of wtg Detailed curves

Load Flow - Fast De-coupled Technique : 0

Number of zones

Print option

Plot option

No Frequency Dependent Load Flow, control option:

Base MVA

Nominal system Frequency ( $\mathrm{Hz}$ )

Frequency Deviation ( $\mathrm{Hz}$ )

Flows in MW and MVAr, option

slack Bus

Transformer Tap control option

$Q$ Checking Limit (Enabled)

Rea1 Power Tolerance (p.u.)

Reactive Power Tolerance (p.u.)

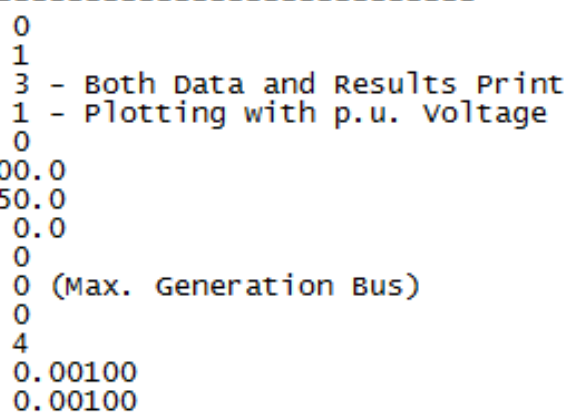




\section{CONCLUSION}

This paper represents the short circuit analysis and contingency analysis for the IEEE 14 bus system by using Mi power software 9.1 in which the transient and sub transient reactance of the components in a system are monitored and the stability of the system has been improved. The sequence impedances are considered and the system has been designed accordingly to improve the performance. Hence the project concludes "the performance of the IEEE-14 bus system" by implementing the calculation of short circuit analysis and contingency analysis for improving by considering the stability criteria to maintain the system as a stable system.

\section{REFERENCES}

[1]. Muhammad Aman Ullah \& Abdul Rehman Abbasi, "Load Flow, Voltage Stability \& Short Circuit Analyses and Remedies for A 1240 MW Combined Cycle Power Plant Using ETAP” IEEE Trans. Power Syst., vol.10, no.1109, ICIEECT.2017.7916568, 5-7 April 2017.

[2]. R. Mageshvaran, I.J. Raglend, V. Yuvaraj, P.G. Rizwan khan, T. Vijayakumar, Sudheera, "Implementation of Non-Traditional Optimization Techniques (PSO CPSO HDE) for the Optimal Load Flow Solution", TENC0N2008- 2008 IEEE Region 10 Conference, pp.19-21, Nov 2008

[3]. Archana R, A.Subramaniya Siva "A Perspective Analysis for the Impact of PVand Wind Hybrid Distributed Generation Using ETAP", International Journal of Advanced Research in Electrical, Electronics and Instrumentation Engineering, Volume 7 issue 4-April 2018.

[4]. Prabhu A, Priyadarshini S.A," Design of Electrical System Using Mi Power on Load Flow and Stability Analysis", Imperial Journal of Interdisciplinary Research (IJIR), Vol3, Issue 122017.

[5]. Mr.A.Subramaniya Siva, Ms.N.Vinothini Imperial Journal of Interdisciplinary Research Enhancement of Harmonics by Shunt Active Power Filter by Id-Iq Method Vol 4,Issue 1, Jan 18.

[6]. R.Manivasagam, Dharmalingam, Velayutham "Power Quality Problem Mitigation by Unified Power Quality Conditioner: An Adaptive Hysteresis Control Technique”, International Journal of Power Electronics(IJPE), Volume 6, No.4, 2014, P.No- 403-425.'.Inderscience Enterprises Ltd.

[7]. Dhayalini. K, 2017, 'Hybrid Particle Swarm Optimization - Genetic Algorithm Based Optimal Dispatch of Wind and Thermal System, Asian Journal of Research in Social Sciences and Humanities, vol. 7, no.1, pp 364 -383.

[8]. A.Subramaniya Siva, M. Bhavani "Mitigation of Harmonics by Shunt Active Power Filter using Synchronous Detection Method", International Journal of Engineering Trends \& Technology (IJETT), Volume 4 issue 6-2013

\section{BIOGRAPHIES}

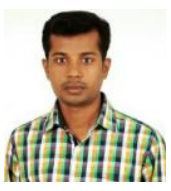

A.Prabhu, is a Assistant Professor, in EEE Department in K.Ramakrishnan College of Engineering, Trichy, Tamilnadu. He completed his BE in Electrical at V.S.B Engineering College Karur. He completed his M.E in Power Systems Engineering at K.Ramakrishnan College of Engineering, Trichy. His research interests are Power Systems, electronic devices, electrical machines, and transmission and switch gears.

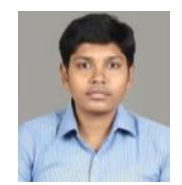

A. Subramaniya Siva, is a Assistant Professor, in EEE Department at K.Ramakrishnan College of Engineering, Trichy, Tamilnadu. He completed his BE in Electrical at P.T.R Engineering College Madurai. He completed his M.E in Power Systems Engineering at Anna University Regional Centre Madurai. His research interests are Power Systems, Renewable Energy, electrical machines, Distributed Generation, transmission \& distribution. 